\title{
Unusual association of non-anaplastic Wilms tumor and Cornelia de Lange syndrome: case report
}

\author{
Claudia Santoro, Andrea Apicella, Fiorina Casale, Angela La Manna, Martina Di Martino, Daniela Di Pinto, \\ Cristiana Indolfi and Silverio Perrotta*
}

\begin{abstract}
Background: Cornelia de Lange syndrome is the prototype for cohesinopathy disorders, which are characterized by defects in chromosome segregation. Kidney malformations, including nephrogenic rests, are common in Cornelia de Lange syndrome. Only one post-mortem case report has described an association between Wilms tumor and Cornelia de Lange syndrome. Here, we describe the first case of a living child with both diseases.

Case presentation: Non-anaplastic triphasic nephroblastoma was diagnosed in a patient carrying a not yet reported mutation in NIPBL (c.4920 G > A). The patient had the typical facial appearance and intellectual disability associated with Cornelia de Lange syndrome in absence of limb involvement. The child's kidneys were examined by ultrasound at 2 years of age to exclude kidney abnormalities associated with the syndrome. She underwent pre-operative chemotherapy and nephrectomy. Seven months later she was healthy and without residual detectable disease.

Conclusion: The previous report of such co-occurrence, together with our report and previous reports of nephrogenic rests, led us to wonder if there may be any causal relationship between these two rare entities. The wingless/integrated (Wnt) pathway, which is implicated in kidney development, is constitutively activated in approximately $15-20 \%$ of all non-anaplastic Wilms tumors. Interestingly, the Wnt pathway was recently found to be perturbed in a zebrafish model of Cornelia de Lange syndrome. Mutations in cohesin complex genes and regulators have also been identified in several types of cancers. On the other hand, there is no clear evidence of an increased risk of cancer in Cornelia de Lange syndrome, and no other similar cases have been published since the fist one reported by Cohen, and this prompts to think Wilms tumor and Cornelia de Lange syndrome occurred together in our patient by chance.
\end{abstract}

Keywords: Cornelia de Lange Syndrome, Wilms tumor, NIPLB, Cohesins, Wht pathway

\section{Background}

Cornelia de Lange syndrome (CdLS, OMIM 608667) is the prototype for cohesinopathy disorders, which are developmental disorders with mutations in an evolutionarily conserved complex that functions in sister chromatin cohesion. However, the complex is also implicated in an increasing number of functions, including transcription regulation, DNA repair, chromosome condensation, and homolog pairing [1]. The CdLS phenotype is widely

\footnotetext{
* Correspondence: silverio.perrotta@unina2.it

Dipartimento della Donna, del Bambino e di Chirurgia Generale e

Specialistica, Seconda Università degli Studi di Napoli, Via Luigi De Crecchio 4, Naples 80138, Italy
}

heterogeneous but characterized mainly by distinctive facial features, growth and cognitive retardation, limb defects, and a range of other malformations of the heart and kidney, among others [2]. Approximately $60 \%$ of CdLS patients have mutations in NIPBL [3-6], and approximately $5 \%$ have mutations in one of the other cohesin-associated genes, including SMC1A, SMC3, $H D A C 8$, and RAD21 [7-10]. Almost all of these mutations are de novo.

Genotype-phenotype correlations have been reported for these CdLS-associated mutations. For example, NIPBL mutations are typically found in patients with classical CdLS features, with missense mutations giving 
rise to milder phenotypes. In contrast, mutations in SMC1A or SMC3 are associated with fewer structural anomalies and consistently with intellectual disability. Mutations in $H D A C 8$ and $R A D 21$ are now recognized as being associated with milder phenotypes without limb involvement and with atypical phenotypes with milder cognitive involvement and typical facial features [11-13]. Increased knowledge about the genetic basis of CdLS has led to an expansion of the phenotype and speculation that the prevalence of CdLS, first estimated to be $1.24 / 100,000$ births, may actually be higher $(\sim 1 / 10,000)$.

CdLS is commonly associated with a wide range of renal abnormalities [2, 14], including nephrogenic rests $[15,16]$. To the best of our knowledge, only one case of Wilms tumor (WT) and CdLS has been reported in the literature. The case was a post-mortem finding in a girl who died of bronchopneumonia at 7 months of age [17]. Here, we report a second case of the co-occurrence of WT and CdLS in a 3-year-old girl, the first in a living child. The tumor was detected by ultrasound examination at the age of 2 years that was performed as part of a routine exam because of the CdLS syndrome. This co-occurrence prompted us to question whether CdLS could have predisposed the patient to developing WT or whether the two entities co-occurred by chance.

\section{Case presentation}

The patient, a 4-year-old girl, was the second child of a healthy, nonconsanguineous couple. The family history was negative for genetic diseases, and the child was born after a normal gestation by vaginal delivery. Her birth weight was $2.600 \mathrm{~g}$ ( $5^{\text {th }}$ percentile), her length was $47 \mathrm{~cm}$ $\left(10^{\text {th }}\right.$ percentile), and her occipitofrontal circumference (OFC) was $30.5 \mathrm{~cm} \mathrm{(}<3^{\text {rd }}$ percentile). The following features were noted at birth: a high palate, synophrys, low-set hairline, a small up-turned nose, a single transverse palmar crease, and hypertrichosis of the face and the back. No major hand malformations were detected, and an examination of the kidneys and urinary tract showed no anomalies. The phenotype was mild (total score 14) according to the clinical score suggested by Selicorni et al. [6]. The standard karyotype was normal. A suspicion of CdLS was confirmed by molecular analysis of NIPBL (NM_133433), which revealed a c.4920 G > A de novo mutation. This variant has never been reported in the literature, ExaC, or the 1000 Genomes browser. The variant is considered disease-causing by prediction tools (i.e., mutation tester) with a high probability score. A perturbation of normal splicing is expected, in fact the mutation affects the last base of exon 24. Moreover, the variant was not present in the patient's parents, confirming its pathogeneticity. A hyperechoic solid mass in the right kidney measuring approximately $3 \mathrm{~cm}$ at its maximum diameter was detected by renal ultrasound scan performed as part of a routine exam at the age of 2 years. The lesion lacked MRI contrast enhancement and initially thought to be benign. However, one year later, ultrasound showed that the mass had grown to a length of $5 \mathrm{~cm}$. Computerized tomography (CT) characterized the lesion as a large enhanced mass protruding from the renal capsule that did not affect vessels or adipose tissue; these findings suggested that the lesion had a malignant nature. A Tru-Cut biopsy revealed non-anaplastic triphasic nephroblastoma, and the patient was treated pre-operatively according to the AIEOP-TW-2003 protocol (i.e., four courses of a regimen of vincristine and actinomycin D). Nephrectomy was then performed, followed by an additional 4 weeks of chemotherapy. At the last follow-up 19 months after treatment, the patient was healthy with no detectable disease, with hypertrophy of the contralateral kidney, $75^{\text {th }}$ percentile according to body surface area (BSA), and a normal glomerular filtration rate $\left(128 \mathrm{~mL} / \mathrm{min} / 1.73 \mathrm{~m}^{2} \mathrm{BSA}\right)$. At that time, the patient's weight was $11.5 \mathrm{~kg}\left(50^{\text {th }}\right.$ percentile for CdLS), height $92 \mathrm{~cm}\left(50^{\text {th }}\right.$ percentile for CdLS), and OFC $42 \mathrm{~cm}\left(50^{\text {th }}\right.$ percentile for CdLS) [18].

\section{Conclusion}

Kidney malformations are commonly seen in CdLS. Selicorni et al. [14] reported a $41 \%$ global incidence of renal abnormalities in pediatric CdLS patients. Although some evidence indicates premature aging in CdLS patients and mutations in cohesin complex genes and regulators have been identified in several types of cancers, the incidence of malignancy does not seem to be increased in CdLS patients compared to the general population $[19,20]$.

There are only single reports of different type of tumors co-occurring with CdLS, including suprasellar germinoma [21], papilloma of the chorioid [22], adenocarcinoma of the esophagus [23], hemangioendothelioma, and WT [17]. The last two were incidental findings at autopsy. The WT seemed to have been non-anaplastic on the basis of the microscopic histological description. The majority of these tumors (i.e., germinoma, hemangioendothelioma, WT) typically occur in childhood. The cohesin network is involved in gene expression during embryogenesis, and the CdLS phenotype clearly reflects the effects of cohesin network disruption on the embryogenesis of various organs and tissues.

Wilms Tumor, or nephroblastoma, is the most common renal tumor in childhood. In 1988-1997, the agestandardized incidence rate of childhood renal tumors in Europe was 8.8 per million, with WT accounting for $93 \%$ of cases [24]. Several genetic syndromes are related 
to a specific, and sometimes quantified, increased risk of WT, but the extreme rarity of the co-occurrence of WT with particular syndromes makes it difficult to establish a direct relationship between the two $[25,26]$. This may also be the case for CdLS and WT.

The disruption of at least three genetic pathways has been linked to tumorigenesis in WTs, partially explaining its heterogeneity [27]. The wingless/integrated (Wnt)/ $\beta$ catenin pathway (canonical Wnt pathway) [28-31] is constitutively activated in approximately $15-20 \%$ of all non-anaplastic WTs; abrogation of the pathway can promote tumorigenesis and nephrogenic rest development [32]. WNT and related signaling pathways also play a crucial role in kidney differentiation and the initiation of nephrogenesis [27].

Pistocchi et al. [33] examined the effects of perturbations in the canonical WNT pathway in a zebrafish model of CdLS with a focus on its expression in the developing central nervous system. These experiments suggested that the WNT pathway is downregulated by a loss-of-function of NIPBL. The interaction between cohesin and WNT pathways is of great interest because WNT plays a role in the non-anaplastic forms of WT, which is the histological type in the patient reported here. Unfortunately, we could not retrieve the biopsied tissue.

To the best of our knowledge, this is the second report of WT associated with CdLS and the first report in a living patient. We explored whether the cooccurrence is stochastic or represents one possible scenario of kidney involvement due to CdLS. The latter hypothesis may be supported by the known role of the cohesin network in embryogenesis and by some reports of nephrogenic rests in CdLS [16]. Notably, nephrogenic rests are considered potential direct precursors of WT [34]. These observations led also to the hypothesis that WT tumorigenesis results from postnatal retention and dysregulated differentiation of blastemal elements in the kidney. Finally, a potential association between CdLS and WT may be underestimated because of spontaneous WT resolution, a misdiagnosis of nephrogenic rests, or a milder misdiagnosed CdLS phenotype. However, no other similar reports have been published in recent decades, and nephrogenic rests are found in $1 \%$ of unselected pediatric autopsies $[35,36]$. This rather prompts to think WT and CdLS occurred together by chance.

In conclusion, we reported the unusual co-occurrence of CdLS and WT, raising questions about an increased risk of WT development in patients with CdLS. Larger population studies are needed. To the best of our knowledge, WT has not been reported in cohesinopathies other than CdLS. Ultrasound screening during childhood is still indicated in CdLS because of the high prevalence of urogenital anomalies.

\section{Abbreviations}

CdLS, Cornelia de Lange Syndrome ; WT, Wilms tumor; CT, computerized tomography; Wnt, wingless/integrated

\section{Acknowledgments}

We are grateful to Prof. Angelo Selicorni for expert advice and support. We also thank the patient and her parents.

\section{Authors' contribution}

$C S, A A, F C$, and SP were the principal investigators and take primary responsibility for the paper; $\mathrm{ALM}, \mathrm{MDM}, \mathrm{DDP}$, and $\mathrm{Cl}$ recruited the patient; $\mathrm{CS}$, AA, ALM, and SP wrote the paper; all authors reviewed the draft and approved the final version of the manuscript.

\section{Competing interests}

The authors declare that they have no competing interests.

\section{Consent for publication}

Written informed consent was obtained from the patient's parents for publication of this case report. A copy of the written consent is available for review by the Editor-in-Chief of this journal.

Received: 9 June 2015 Accepted: 9 June 2016

Published online: 13 June 2016

References

1. Mehta GD, Kumar R, Srivastava S, Ghosh SK. Cohesin: functions beyond sister chromatid cohesion. FEBS Lett. 2013;587:2299-312.

2. Jackson L, Kline AD, Barr MA, de Koch S. Lange syndrome: a clinical review of 310 individuals. Am J Med Genet. 1993:47:940-6.

3. Bork G, Redon R, Sanlaville D, Rio M, Pireur M, Lyonnet S, et al. NIPBL mutations and genetic heterogeneity in Cornelia de Lange syndrome. J Med Genet. 2004;41, e128.

4. Bhuiyan ZA, Klein M, Hammond $P$, van Haeringen A, Mannens MM, Van Berckelaer-Onnes I, Hennekam RC. Genotype-phenotype correlations of 39 patients with Cornelia De Lange syndrome: the Dutch experience. J Med Genet. 2006:43:568-75.

5. Yan J, Saifi GM, Wierzba TH, Withers M, Bien-Willner GA, Limon J, et al. Mutational and genotype-phenotype correlation analyses in 28 Polish patients with Cornelia de Lange syndrome. Am J Med Genet A. 2006;140:1531-41.

6. Selicorni A, Russo S, Gervasini C, Castronovo P, Milani D, Cavalleri F, et al. Clinical score of 62 Italian patients with Cornelia de Lange syndrome and correlations with the presence and type of NIPBL mutation. Clin Genet. 2007;72:98-108.

7. Musio A, Selicorni A, Focarelli ML, Gervasini C, Milani D, Russo S, et al. X-linked Cornelia de Lange syndrome owing to SMC1L1 mutations. Nat Genet. 2006;38:528-30.

8. Deardorff MA, Kaur M, Yaeger D, Rampuria A, Korolev S, Pie J, et al. Mutations in cohesin complex members SMC3 and SMC1A cause a mild variant of cornelia de Lange syndrome with predominant mental retardation. Am J Hum Genet. 2007:80:485-94.

9. Deardorff MA, Wilde JJ, Albrecht M, Dickinson E, Tennstedt S, Braunholz D, et al. RAD21 mutations cause a humancohesinopathy. Am J Hum Genet b. 2012;90:1014-27.

10. Deardorff MA, Bando M, Nakato R, Watrin E, Itoh T, Minamino M, et al. HDAC8 mutations in Cornelia de Lange syndrome affect the cohesin acetylationcycle. Nature. 2012;489:313-7.

11. Mannini L, Cucco F, Quarantotti V, Krantz ID, Musio A. Mutation Spectrum and Genotype-Phenotype Correlationin Cornelia de Lange Syndrome. Hum Mutat. 2013;34:1589-96.

12. Gervasini C, Russo S, Cereda A, Parenti I, Masciadri M, Azzollini J, et al. Am J Med Genet A. 2013;161A:2909-19.

13. Gillis LA, McCallum J, Kaur M, DeScipio C, Yaeger D, Mariani A, et al. NIPBL mutational analysis in 120 individuals with Cornelia de Lange syndrome and evaluation of genotype-phenotype correlations. Am J Hum Genet. 2004;75:610-23.

14. Selicorni A, Sforzini C, Milani D, Cagnoli G, Fossali E, Bianchetti MG. Anomalies of the kidney and urinary tract are common in de Lange syndrome. Am J Med Genet A. 2005;132A:395-7.

15. Cohen Jr M. The child with multiple defects. New York: Raven; 1982. p. 189. 
16. Charles AK, Porter HJ, Sams V, Lunt P. Nephrogenic rests and renal abnormalities in Brachmann-de Lange syndrome. Pediatr Pathol Lab Med. 1997;17:209-19.

17. Maruiwa M, Nakamura $Y$, Motomura K, Murakami T, Kojiro M, Kato M, et al. Cornelia de Lange syndrome associated with Wilms' tumour and infantile haemangioendothelioma of the liver: report of two autopsy cases. Virchows Arch A Pathol Anat Histopathol. 1988;413:463-8.

18. Kline AD, Barr M, Jackson LG. Growth manifestations in the Brachmann-de Lange syndrome. Am J Med Genet. 1993;47:1042-9.

19. Kline AD, Calof AL, Schaaf CA, Krantz ID, Jyonouchi S, Yokomori K, et al. Cornelia de Lange syndrome: further delineation of phenotype, cohesin biology and educational focus, 5th Biennial Scientific and Educational Symposium abstracts. Am J Med Genet A. 2014;164:1384-93.

20. Schrier SA, Sherer I, Deardorff MA, Clark D, Audette L, Gillis L, et al. Causes of death and autopsy findings in a large study cohort of individuals with Cornelia de Lange syndrome and review of the literature. Am J Med Genet A. 2011;155A:3007-24.

21. Sugita K, Izumi T, Yamaguchi K, Fukuyama Y, Sato A, Kajita A. Cornelia de Lange syndrome associated with a suprasellar germinoma. Brain Dev. 1986;8:541-6.

22. Chico-Ponce de León F, Gordillo-Domínguez LF, González-Carranza V, Torres-García S, García-Delgado C, Sánchez-Boiso A, et al. BrachmannCornelia de Lange syndrome with a papilloma of the choroid plexus: analyses of molecular genetic characteristics of the patient and the tumor. A single-case study. Childs Nerv Syst. 2015;31:141-6.

23. DuVall GA, Walden DT. Adenocarcinoma of the esophagus complicating Cornelia de Lange syndrome. J Clin Gastroenterol. 1996;22:131-3.

24. Pastore G, Znaor A, Spreafico F, Graf N, Pritchard-Jones K, Steliarova-Foucher E. Malignant renal tumours incidence and survival in European children (1978-1997): report from the Automated Childhood Cancer Information System project. Eur J Cancer. 2006;42:2103-14.

25. Scott RH, Stiller CA, Walker L, Rahman N. Syndromes and constitutional chromosomal abnormalities associated with Wilms tumour. J Med Genet. 2006:43:705-15.

26. Dumoucel $S$, Gauthier-Villars M, Stoppa-Lyonnet D, Parisot P, Brisse $H$, Philippe-Chomette $P$, et al. Malformations, genetic abnormalities, and Wilms tumor. Pediatr Blood Cancer. 2014;61:140-4.

27. Perotti $\mathrm{D}$, Hohenstein $\mathrm{P}$, Bongarzone I, Maschietto $\mathrm{M}$, Weeks $\mathrm{M}$, Radice $\mathrm{P}$, et al. Is Wilms tumor a candidate neoplasia for treatment with WNT/B-catenin pathway modulators? A report from the renal tumors biology-driven drug development workshop. Mol Cancer Ther. 2013;12:2619-27.

28. Fukuzawa R, Anaka MR, Heathcott RW, McNoe LA, Morison IM, Perlman EJ, et al. Wilms tumour histology is determined by distinct types of precursor lesions and not epigenetic changes. J Pathol. 2008;215:377-87.

29. Koesters R, Ridder R, Kopp-Schneider A, Betts D, Adams V, Niggli F, et al. Mutational activation of the beta-catenin proto-oncogene is a common event in the development of Wilms' tumors. Cancer Res. 1999;59:3880-2.

30. Li CM, Kim CE, Margolin AA, Guo M, Zhu J, Mason JM, Hensle TW, et al. CTNNB1 mutations and overexpression of Wnt/beta-catenin target genes in WT1-mutant Wilms' tumors. Am J Pathol. 2004;165:1943-53.

31. Maiti S, Alam R, Amos Cl, Huff V. Frequent association of beta-catenin and WT1 mutations in Wilms tumors. Cancer Res. 2000;60:6288-92.

32. Fukuzawa R, Heathcott RW, Sano M, Morison IM, Yun K, Reeve AE. Myogenesis in Wilms' tumors is associated with mutations of the WT1 gene and activation of BCl-2 and the Wnt signaling pathway. Pediatr Dev Pathol. 2004;7:125-37.

33. Pistocchi A, Fazio G, Cereda A, Ferrari L, Bettini LR, Messina G, et al. Cornelia de Lange Syndrome: NIPBL haploinsufficiency downregulates canonical Wnt pathway in zebrafish embryos and patients fibroblasts. Cell Death Dis. 2013;4, e866.

34. Beckwith JB. Nephrogenic rests and the pathogenesis of Wilms tumor: developmental and clinical considerations. Am J Med Genet. 1998;79:268-73.

35. Beckwith JB. Precursor lesions of Wilms tumor: clinical and biological implications. Med Pediatr Oncol. 1993;21:158-68.

36. Beckwith JB. New developments in the pathology of Wilms tumor. Cancer Invest. 1997;15:153-62

\section{Submit your next manuscript to BioMed Central and we will help you at every step:}

- We accept pre-submission inquiries

- Our selector tool helps you to find the most relevant journal

- We provide round the clock customer support

- Convenient online submission

- Thorough peer review

- Inclusion in PubMed and all major indexing services

- Maximum visibility for your research

Submit your manuscript at www.biomedcentral.com/submit
Biomed Central 